\title{
Transformações do bairro da Vila Olímpia em São Paulo, Brasil (2000 a 2013) e as percepções da hospitalidade no espaço urbano.
}

\section{Transformations of Vila Olímpia District in São Paulo, Brazil (2000-2013) and the hospitality perceptions in the urban space}

\author{
Luciana Lagares Gonzalez (GONZALEZ, L. L.)* \\ Maria Ângela de Abreu Cabianca (CABIANCA, M. A. de A.) ${ }^{* *}$
}

\begin{abstract}
RESUMO - Neste artigo teve-se por objetivo analisar as percepções de moradores e trabalhadores do bairro da Vila Olímpia na cidade de São Paulo (Brasil), entre os anos de 2000 e 2013, tendo como recorte geográfico as Ruas Quatá, Olimpíadas, Vicente Pinzón, Dr. Cardoso de Melo e Avenida Santo Amaro e ainda, associar essas percepções às dimensões da hospitalidade exercida em espaços urbanos. A metodologia utilizada foi a pesquisa qualitativa de caráter exploratório, apoiada por entrevistas com moradores/trabalhadores do Bairro há pelo menos quinze anos. Os resultados obtidos possibilitaram confirmar que as dimensões de acessibilidade, legibilidade e identidade estão presentes na Vila Olímpia. Apesar de revelarem uma nova percepção da hospitalidade do bairro, os entrevistados demonstraram preferência pelos novos espaços, nos quais afirmaram possuir maior praticidade e valorização social, o que demonstrou ter se estabelecido uma nova relação de hospitalidade.
\end{abstract}

Palavras-chave: Hospitalidade; Urbanismo; Vila Olímpia; Percepções; Usuários.

ABSTRACT - This article aimed to analyze the perceptions of residents and workers in Vila Olimpia neighborhood in São Paulo, between the years 2000 and 2013, with the geographic divisions of streets Quatá, Olimpíadas, Vicente Pinzon, Dr. Cardoso de Melo and Santo Amaro Avenue, and also associate these perceptions to the dimensions of hospitality exercised in urban spaces. The methodology used was a qualitative exploratory research, supported by interviews with residents/workers of this neighborhood for at least fifteen years. The results enabled us to confirm that the dimensions of accessibility, legibility and identity are present in Vila Olimpia. While revealing a new perception of the hospitality in this neighborhood, respondents showed preference for new spaces, in which these said that there is more practical and social value, which showed that have been established a new relationship of hospitality.

Key words: Hospitality; Urbanism; Vila Olímpia; Perceptions; Users.

\footnotetext{
Formação: Graduação (Administração de Empresas/ UNIB); Mestrado em Hospitalidade pela Universidade Anhembi Morumbi. Endereço físico para correspondência: Rua Francisco Dias Velho, 66 apto 45 - Brooklin. CEP: 04581-000 - São Paulo - São Paulo (Brasil). Telefone para contato: 55119 9414-8982. E-mail: luciana-lagares@ hotmail.com

*** Formação: Graduação em Ecologia pelo Instituto de Biociências da Universidade Estadual Paulista "Júlio de Mesquita Filho" (IB/UNESP, Campus Rio Claro) e em Geografia pela Faculdade de Filosofia, Letras e Ciências Humanas da Universidade de São Paulo (FFLCH/USP); Mestrado em Ecologia (IB/USP); Doutorado em Saúde Ambiental pela Faculdade de Saúde Pública da Universidade de São Paulo (FSP/USP). Atividade profissional: Docente dos cursos de Arquitetura e Urbanismo, Turismo, Hotelaria e Ciências Biológicas; e colaboradora do Programa de Pós Graduação em Hospitalidade da Universidade Anhembi Morumbi. Endereço físico para correspondência: Rua Casa do Ator, 275. Vila Olímpia. CEP: 04546-001 - São Paulo - São Paulo (Brasil). Telefone para contato: 5511 38473037. Email: mangela@anhembimorumbi.edu.br
} 


\section{INTRODUÇÃO}

Ao longo das últimas décadas, as intervenções urbanas na cidade de São Paulo ocorreram em todas as suas zonas administrativas, buscando a melhoria da infraestrutura e da qualidade de vida da população. Segundo Fix (2007), desde a gestão do prefeito Faria Lima (1965-1969) essas alterações foram se tornando mais evidentes na cidade. A autora considera que as intervenções da Operação Urbana Faria Lima, Operação Urbana Consorciada Água Espraiada e do Movimento Colmeia no bairro da Vila Olímpia produziram modificações que transformaram um bairro primordialmente residencial e com pouca representatividade na vida econômica e empresarial da cidade, em um dos bairros com maior potencial construtivo para comportar edifícios de grandes lajes e instalações tecnológicas de última geração. Por ter adquirido estas características, o bairro passou a ser popularmente conhecido como Vale do Silício brasileiro, sobretudo pelo mercado imobiliário, ávido por trazer aos investidores a associação desta região paulistana, de grande e rápida expansão empresarial, com a região californiana que, também na década de 90, despontou como polo produtor de tecnologia da informação. As mudanças verificadas no bairro da Vila Olímpia, a partir de então, repercutiram de diferentes maneiras na vida das pessoas que habitavam ou circulavam pelo bairro.

Neste estudo buscou-se detectar a percepção de moradores do bairro da Vila Olímpia, em relação às alterações urbanas ocorridas entre os anos de 2000 e 2013 e, com isso, associar estas percepções com a hospitalidade presente neste espaço. Através de uma pesquisa de caráter exploratório, documental e com o uso de entrevistas semiestruturadas, intencionou-se captar as percepções de pessoas que residiam ou trabalhavam no bairro da Vila Olímpia há ao menos quinze (15) anos, e, assim, avaliar a hospitalidade oferecida por este espaço urbano, utilizando as dimensões da hospitalidade urbana definidas por Grinover (2007) e também estudadas por Ferraz (2013).

O recorte geográfico definido para este estudo ficou compreendido entre as Ruas Quatá, Olimpíadas, Vicente Pinzón, Dr. Cardoso de Melo e Avenida Santo Amaro. Neste perímetro, onde se observam amplos edifícios comerciais, sedes de empresas multinacionais, hotéis de redes nacionais e internacionais, antigas casas residenciais transformadas em estabelecimentos comerciais, também verificam-se residências 
localizadas em pequenas vilas, construídas na década de 1950 e 1960, com financiamento da Caixa Econômica Federal (FRUGOLI JR., 2001).

\section{O BAIRRO DA VILA OLÍMPIA NA CIDADE DE SÃO PAULO}

O bairro da Vila Olímpia pertence ao distrito do Itaim Bibi, que, por sua vez, pertence à subprefeitura de Pinheiros (imagem 1). Está situado na região Sudoeste da cidade de São Paulo, tendo como bairros vizinhos a Vila Nova Conceição, Vila Uberabinha (popularmente chamado de Moema), Brooklin Novo e a Avenida Marginal do Rio Pinheiros (BAIRROVILAOLÍMPIA, 2004).

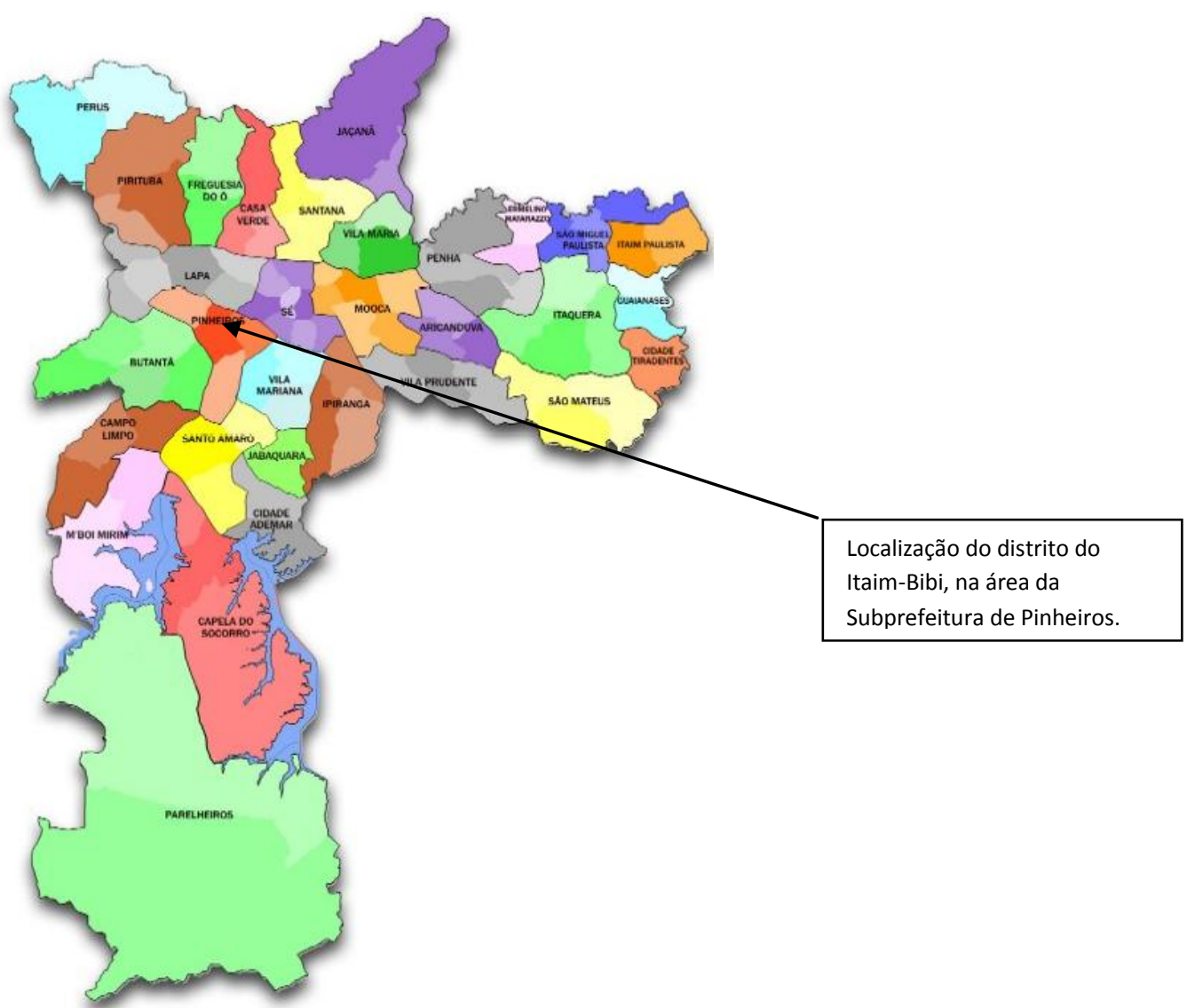

IMAGEM 1 - MAPA DAS SUBPREFEITURAS DO MUNICIPIO DE SÃO PAULO, COM A DELIMITAÇÃO DOS DISTRITOS QUE COMPÕEM CADA SUBPREFEITURA. EM DESTAQUE, A LOCALIZAÇÃO DA PREFEITURA DE PINHEIROS, QUE ABRIGA O DISTRITO DO ITAIM BIBI, ONDE SE LOCALIZA O BAIRRO DA VILA OLÍMPIA.

FONTE: Prefeitura do Município de São Paulo ${ }^{1}$.

\footnotetext{
${ }^{1}$ Disponível em:

$<$ http://www.prefeitura.sp.gov.br/cidade/secretarias/subprefeituras/subprefeituras/mapa/index.php?p=148 94>.
} 
Durante cerca de sessenta anos a Vila Olímpia apresentou características basicamente residenciais/rurais, com chácaras de cultivo de flores, vilas residenciais, cujas casas eram construídas quase sempre, com financiamento da Caixa Econômica Federal, edifícios residenciais com poucos pavimentos, pequenos estabelecimentos comerciais e alguns galpões, sobretudo na parte baixa ${ }^{2}$ do bairro, onde era comum ocorrer inundações (RIBEIRO, 2004), como a registrada na imagem 2.

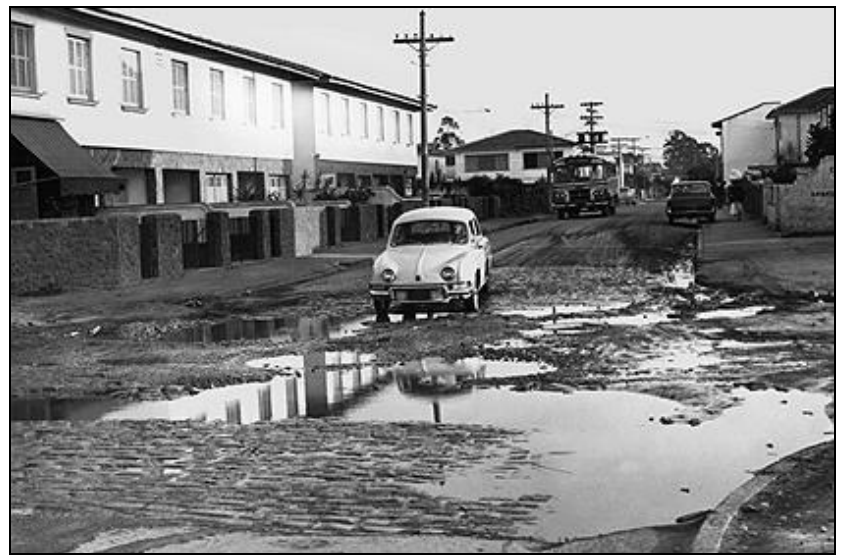

IMAGEM 2 - RUA NOVA CIDADE EM 1966.

FONTE: REVISTA VEJA SP (2013).

Conforme verificado por FIX (2001), as mudanças mais significativas ocorreram após a canalização dos córregos Uberaba e Uberabinha e a eliminação das favelas JK e Funchal, no final dos anos 1990. Segundo a autora, estas ações, previstas na Operação Urbana Faria Lima ${ }^{3}$, tinham como objetivo inicial interligar a região Oeste à região Sul da cidade de São Paulo por meio de uma via expressa que passaria pelo bairro. Porém, após décadas sem a realização das ações inicialmente propostas e as diversas alterações de projeto que ocorreram, as desapropriações tornaram-se inviáveis, mantendo a Vila Olímpia com status de bairro pouco atrativo e desconhecido dos paulistanos (FIX, 2001).

\footnotetext{
${ }^{2}$ A partir da Rua Nova Cidade até a Avenida Nações Unidas (Marginal do Rio Pinheiros).

${ }^{3}$ Segundo o Portal da Prefeitura do Município de São Paulo, "um dos objetivos do Estatuto da Cidade (Lei Federal n. 10.257 de 10 de julho de 2001) ao prever as Operações Urbanas Consorciadas (OUC), instrumento cujo objetivo é gerar transformações urbanísticas estruturais, melhorias sociais e valorização ambiental de determinadas regiões do Município, por meio da elaboração de um projeto urbanístico específico. As áreas de interesse para Operações Urbanas de São Paulo são previstas no Plano Diretor Estratégico (PDE), aprovado em 2002, e buscam estabelecer um marco regulatório para regiões estratégicas."
} 
Numa Operação Urbana a região recebe investimentos privados a partir de benefícios e incentivos dados pela Prefeitura, como o aumento de Potencial Construtivo, que pode ser adquirido com a compra de CEPAC's - Certificado de Potencial Adicional de Construção - (PMSP, 2013).

Segundo reportagem do Jornal Folha de São Paulo de 4/11/2012, a criação do Movimento Colmeia por parte de um grupo de moradores, empresários, comerciantes do bairro, juntamente com representantes da Prefeitura de São Paulo, promoveu melhorias na infraestrutura da parte baixa do bairro, como o recapeamento de ruas, alargamento de calçadas e aterramento da fiação. Isto fez com que a Vila Olímpia conquistasse maior destaque no mercado imobiliário, tornando-se um dos bairros com maior volume de investimento em construção de edifícios comerciais. Tais mudanças aceleraram o processo de verticalização verificado no bairro e constatado na imagem 3 , que evidencia a presença de edifícios de maior gabarito nas imediações da Rua das Olimpíadas.

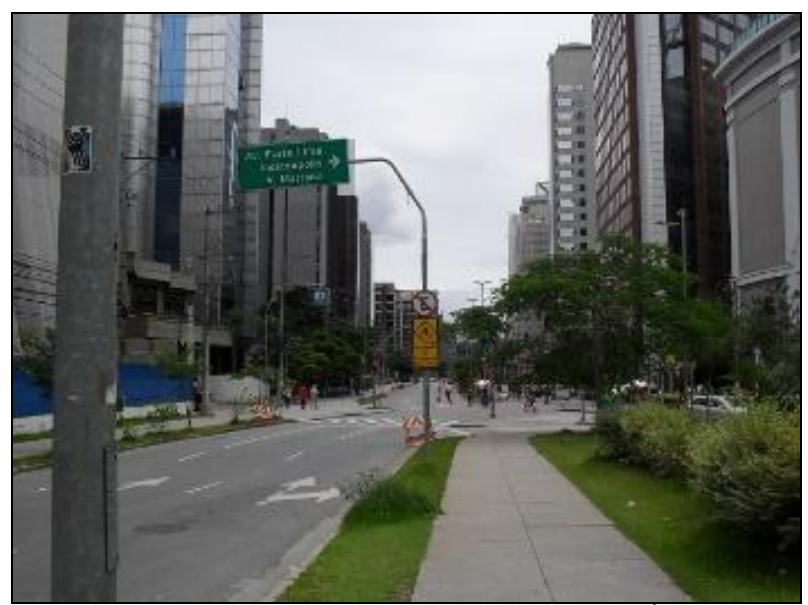

IMAGEM 3 - PARTE BAIXA DA VILA OLÍMPIA (RUA OLIMPÍADAS). FONTE: ARQUIVO PESSOAL (2013).

Como resultado das intervenções urbanas produzidas pela Operação Urbana Faria Lima e pelo Movimento Colmeia, a Vila Olímpia passou a ser reconhecida como um bairro que comporta escritórios de grandes empresas, com farto comércio gastronômico e de diversão noturna (baladas), passando a ser considerado um bairro de alto padrão social (FIX, 2007). 


\section{HOSPITALIDADE EM ESPAÇOS URBANOS}

A caracterização de um espaço urbano requer uma análise que transcende o aspecto material, concreto, visual contido numa cidade, incluindo a relação existente entre espaço e usuário/morador, a infraestrutura (sistema viário, equipamentos urbanos ${ }^{1}$, serviços,) que compõem este espaço e o indivíduo, a pessoa que vive ou utiliza aquele espaço (LYNCH, 2011).

De acordo com Lynch (2011), o morador ou usuário de uma cidade/bairro se utiliza de percepções motoras e sensoriais para compreender o espaço no qual está inserido ou de passagem e, da mesma maneira, para estabelecer uma relação com este espaço. Segundo o autor, para que uma pessoa se sinta segura em um local é necessário que ela consiga se orientar de modo a poder transitar pelo espaço, sabendo onde e como quer chegar. Sendo assim, o senso de localização que o usuário adquire no espaço em questão (cidade, bairro ou região) seria estabelecido pelas imagens e sensações que este último proporcionaria através das relações estabelecidas entre espaço e usuário.

Os sentidos como olfato e audição também são abordados por Lynch (2011) como veículos para estabelecer determinada relação com o espaço por onde se transita, podendo esta ser positiva ou negativa, dependendo da experiência inicial.

Para Kuri (2006) uma cidade é definida pelas atitudes de seus moradores e usuários que, por meio de características culturais, sociais, políticas e de inter-relação, formam a cidade. Características estas que, segundo o autor, podem ser regionais e/ ou globais formando assim, muitas vezes, cidades intercontinentais, pois misturam características de culturas diversas.

Para Lashey e Morrison (2004) as relações entre os seres humanos e destes com o espaço são tratadas pela hospitalidade. $\mathrm{O}$ espaço considerado pelos autores pode ser o espaço doméstico, o espaço público e o espaço comercial.

Grinover (2007) e Ferraz (2013) tratam da hospitalidade oferecida nos espaços urbanos/ públicos. Para melhor estudar estes espaços, Grinover (2007) estabeleceu três dimensões da hospitalidade: a primeira dimensão é a acessibilidade, que possibilita o acesso das pessoas aos lugares, aos equipamentos públicos ${ }^{4}$, às informações. Este

\footnotetext{
4 "Equipamentos urbanos são todos os bens públicos ou privados de utilidade pública, destinados à prestação de serviço para garantir o funcionamento da cidade." (Associação Brasileira de Normas Técnicas (ABNT) - Equipamento Urbano (NBR 9284), 1986).
} 
acesso pode ser físico, como o acesso à água potável, ao transporte coletivo de qualidade; intelectual, como o acesso à educação básica e, ainda, social; como atendimento médico, odontológico ou psicológico, por exemplo, (GRINOVER, 2007).

Legibilidade é a segunda dimensão da hospitalidade abordada por Grinover (2007), também considerada por Lynch (2011), que considera ser este um fator de integração do indivíduo com o meio urbano, quando se trata dos sentidos sensoriais.

Os autores supracitados definem a legibilidade como a maneira com que a cidade ou, neste caso, o bairro, é apreendido por seus moradores e usuários, a partir de pontos de referência. Consideram, ainda que as pessoas conseguem compreender o espaço urbano que frequentam como um conjunto composto por partes que possibilitam o reconhecimento e a sensação de localização e pertencimento a este espaço.

A terceira dimensão da hospitalidade proposta por Grinover (2007) é a identidade, em que se aborda a maneira como as pessoas estabelecem a relação com o espaço. Segundo o autor, esta identidade requer tempo para ser formada, pois depende dos detalhes que a pessoa vincula ao espaço específico ao longo dos tempos para assim criar para si a identidade relacionada a este espaço.

Ferraz (2013) também discute as dimensões da hospitalidade nos espaços urbanos e define como anfitrião de uma cidade a figura pública do prefeito e seus representantes, que são os responsáveis legais pelas tomadas de decisões sobre os destinos de uma cidade. Grinover (2009) considera anfitriões, além do prefeito, os moradores do lugar, pois são eles que constituem esse espaço, transformando-o em lugar de vivência, de convivência, de trabalho, de hospitalidade. Segundo Ferraz (2013), dependem dessas pessoas, além das ações do poder público, as características físicas ou atitudes que podem caracterizar a hospitalidade de um lugar.

\subsection{A HOSPITALIDADE DA VILA OLÍMPIA APÓS O ANO 2000}

As alterações produzidas pela implantação da Operação Urbana Faria Lima e as ações do Movimento Colmeia promoveram intensa movimentação e expansão do mercado imobiliário, verificando-se a necessidade de atender a um novo público, que passou a frequentar a Vila Olímpia para atividades profissionais (JORNAL FOLHA SÃO PAULO, 2012). Como consequência desta movimentação, casas construídas nas 
décadas de 1950 e 1960, como as das imagens 4 e 5, que até o ano 2000 serviam de moradias, passaram a ser transformadas em pequenos estabelecimentos comerciais.
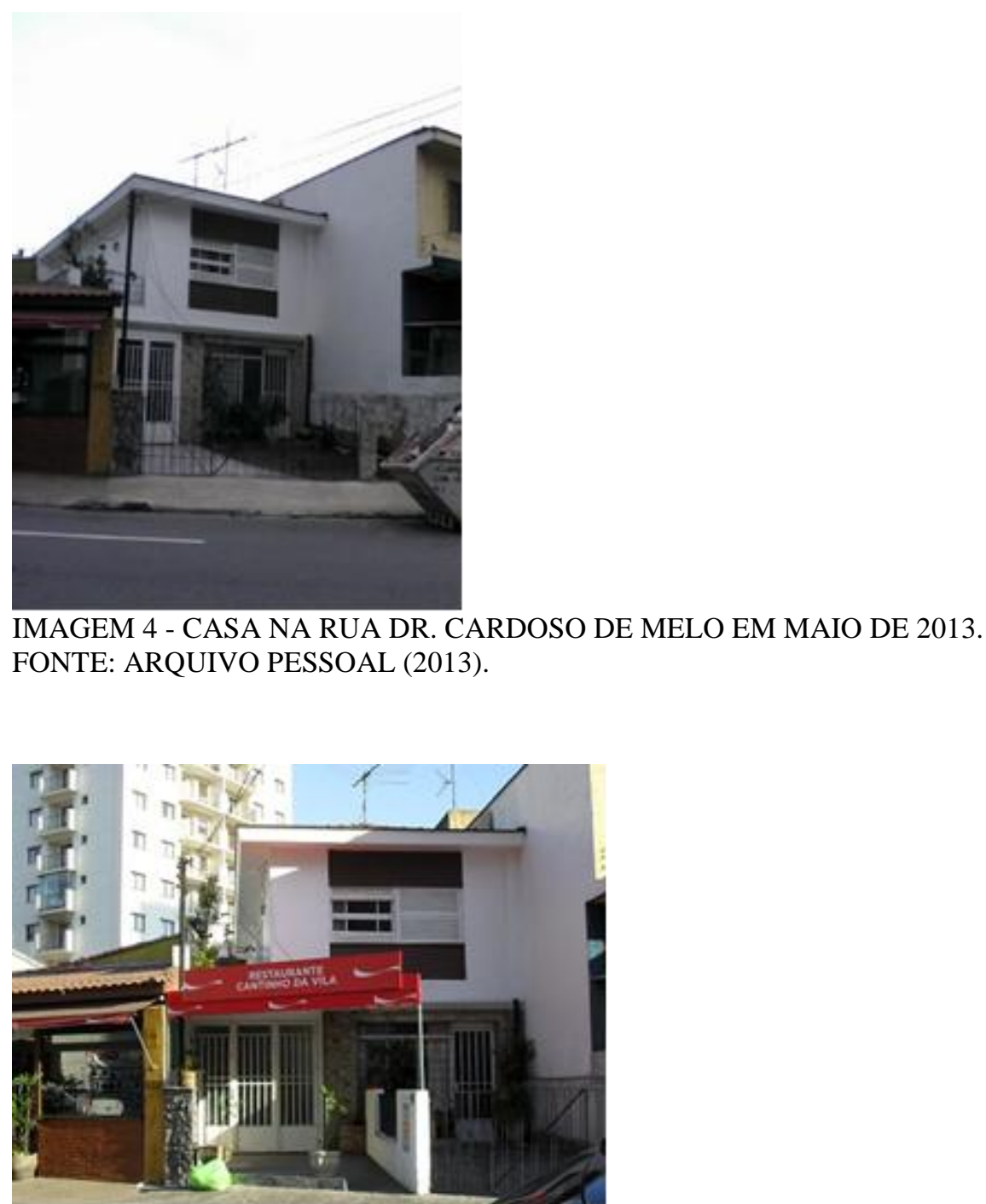

IMAGEM 5 - CASA TRANSFORMADA NA RUA DR. CARDOSO DE MELO EM AGOSTO DE 2013.

FONTE: ARQUIVO PESSOAL (2013).

Segundo matéria do Jornal Folha de São Paulo (2013), assistiu-se nesta região a transformação de um bairro predominantemente residencial para um bairro misto, com potencial comercial construtivo acima de $80 \%$. Isto faz com que se torne mais desafiadora a análise de sua hospitalidade.

Os antigos galpões, na parte baixa do Bairro, foram desativados, dando lugar a edifícios comerciais, como os Shoppings Vila Olímpia e JK Iguatemi, hotéis de grandes redes como o Transamérica, Estanplaza, Caesar Business, Quality Suites e Radisson 
Vila Olímpia, restaurantes de diversos tipos de culinária e ainda, casas de entretenimento noturno (FIX, 2007).

$\mathrm{Na}$ imagem 6 é apresentada a delimitação da área em estudo, compreendida entre as seguintes vias: Avenida Santo Amaro, Rua Dr. Cardoso de Melo, Rua Vicente Pinzón, Rua Olimpíadas e Rua Quatá. Neste recorte geográfico foram detectados mais de cem (100) estabelecimentos voltados para o segmento alimentício, mais de 142 locais que comercializavam roupas e calçados, dentre outros locais que comercializavam produtos ou prestavam serviços. As características observadas no período estudado demonstraram que a hospitalidade doméstica existente anteriormente no Bairro transformou-se em hospitalidade comercial, para atender aos frequentadores e moradores, novos e antigos.

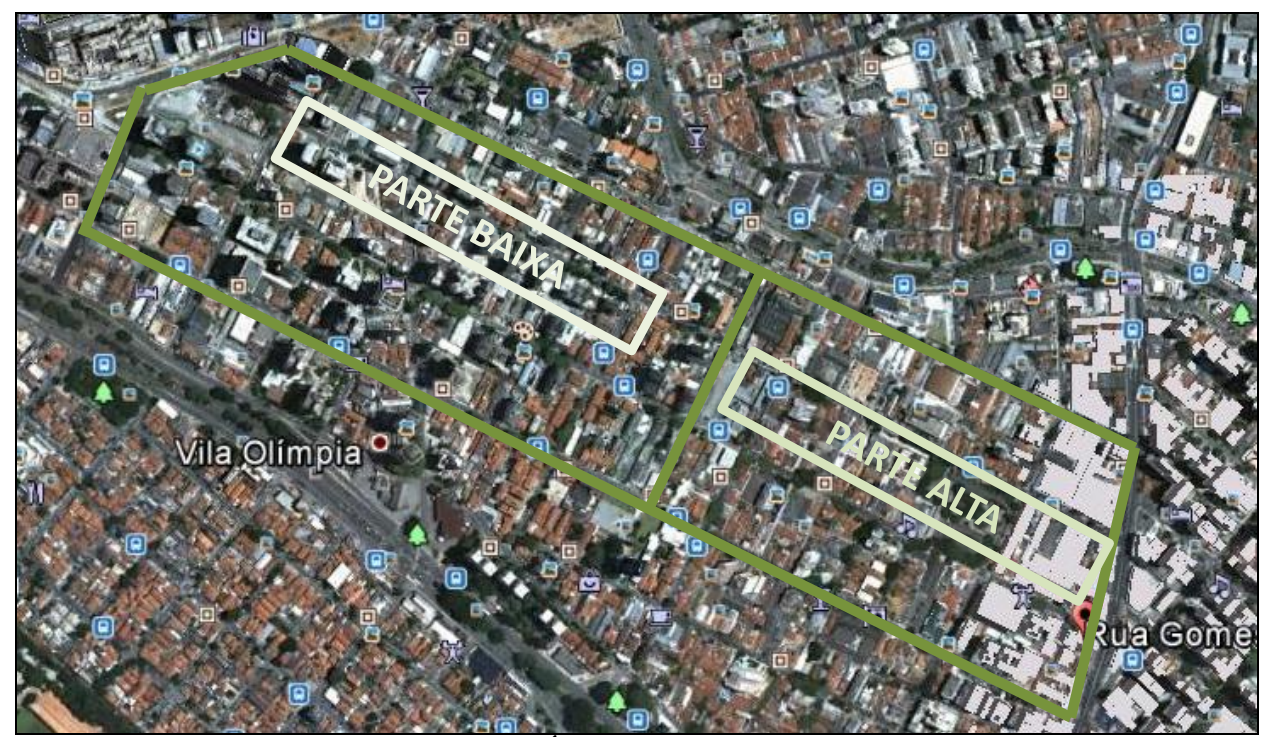

IMAGEM 6 - RECORTE GEOGRÁFICO ESTABELECIDO PARA O ESTUDO. FONTE: GOOGLE EARTH, 2014.

A canalização dos córregos Uberaba e Uberabinha, que melhorou o acesso ao Bairro, remete à dimensão da acessibilidade como parte da hospitalidade urbana, conforme proposto por Grinover (2007), da mesma maneira que a inauguração da estação Vila Olímpia, de trem (CPTM, 2012). Tanto as intervenções dos projetos Operações Urbanas Consorciadas Faria Lima quanto as ações do Movimento Colmeia objetivaram implementar a infraestrutura da parte baixa do bairro da Vila Olímpia, com alargamento de ruas, melhoria no calçamento, melhoria visual, com enterramento de fios e cabos de energia elétrica e transmissão de dados e voz. A instalação de edifícios 
de instituições de ensino superior como a Universidade Anhembi Morumbi e o Insper, a implementação de estabelecimentos hospitalares e de consultórios médicos, muitos deles ocupando antigas residências, evidenciam a melhoria de acesso a serviços de educação e saúde. Tais ações permitem perceber a dimensão de acessibilidade que passou a se estabelecer em todo o Bairro (COLMEIASP, 2012).

\section{RESULTADOS DAS ENTREVISTAS}

Como parte da metodologia utilizada, além da pesquisa qualitativa de caráter exploratório, foram realizadas entrevistas com alguns moradores e trabalhadores do bairro da Vila Olímpia há pelo menos quinze anos, com o objetivo de analisar as suas percepções quanto às alterações urbanas ocorridas neste espaço e assim, associar a presença das dimensões da hospitalidade estabelecidas por Grinover (2007).

No quadro abaixo se sintetiza algumas das características dos entrevistados e sua atuação no bairro:

QUADRO 1 - CARACTERÍSTICAS DOS ENTREVISTADOS

\begin{tabular}{|c|c|c|c|c|}
\hline Entrevistado & Sexo & Atuação no bairro & $\begin{array}{c}\text { Região ocupada no } \\
\text { bairro }\end{array}$ & $\begin{array}{l}\text { Tempo no } \\
\text { bairro }\end{array}$ \\
\hline 1 & Masculino & $\begin{array}{c}\text { Trabalhador (funcionário } \\
\text { de universidade) e } \\
\text { residente }\end{array}$ & $\begin{array}{c}\text { Imediações da Avenida } \\
\text { Santo Amaro - parte } \\
\text { alta } \\
\end{array}$ & Desde 1980 \\
\hline 2 & Feminino & $\begin{array}{l}\text { Trabalhadora (tem banca } \\
\text { de jornal) e residente }\end{array}$ & Rua Ponte Delgada & Desde 1964 \\
\hline 3 & Feminino & $\begin{array}{c}\text { Trabalhadora } \\
\text { (funcionária de um flat) }\end{array}$ & Parte baixa & Desde 1993 \\
\hline 4 & Feminino & $\begin{array}{c}\text { Trabalhadora } \\
\text { (funcionária de um flat) } \\
\end{array}$ & Parte baixa & Desde 1985 \\
\hline 5 & Feminino & Residente & Parte alta & Desde 1979 \\
\hline 6 & Feminino & $\begin{array}{l}\text { Trabalhadora (tem } \\
\text { escritório) e residente }\end{array}$ & Parte alta & Desde 1966 \\
\hline 7 & Feminino & Residente & Parte alta & Desde 1957 \\
\hline
\end{tabular}

Fonte: Pesquisa de campo, 2013. 


\subsection{AS PERCEPÇÕES DOS MORADORES E USUÁRIOS DA VILA OLÍMPIA E A HOSPITALIDADE}

As hipóteses iniciais deste estudo envolviam os impactos produzidos pelas mudanças do bairro na identificação que seus moradores e usuários estabeleciam com ele e em sua percepção da hospitalidade. Para testar estas hipóteses foram feitos levantamentos bibliográficos e documentais, além de pesquisa de campo, que incluiu a obtenção de imagens fotográficas e impressões de moradores e usuários do Bairro que o frequentavam há mais de quinze anos, pois assim, poderiam falar de suas lembranças e percepções das alterações urbanas ocorridas no espaço e período estudado.

Ao serem questionados a respeito das alterações urbanas ocorridas no bairro nos últimos treze anos, os entrevistados demonstraram estar atentos a elas, sendo que a maioria demonstrou a preferência por esta "nova" Vila Olímpia. Os relatos a seguir registram algumas das percepções dos entrevistados:

Na Vila Olímpia, mais na parte de baixo (as alterações urbanas), depois da Nova Cidade (rua) ali, aonde tinham duas favelas. Uma na Hélio Pelegrino (avenida) e uma na Funchal (avenida) na parte de arquitetura, na Funchal, cê vê a diferença. Totalmente diferente. Aí hoje você tem o Shopping Vila Olímpia, que eu moro aqui e ainda nem fui. Nunca fui. Mas era tudo assim, bem estranho. A localização (ponto positivo). Hoje você tem tudo aqui. Você tem shopping perto, que você vai a pé... Tem agora a ciclovia de bicicleta que é importante. O bairro em si, assim, não tem lazer, assim para as crianças. Aqui tudo você tem que pagar. (ENTREVISTADO 1).

A melhoria assim é visível, né? Agora. Quando eu cheguei não tinha shopping... Tem o trem, que antes não tinha, tinha que vir de ônibus... A localização é muito boa... O bairro é melhor agora. Porque antes não tinha esse fluxo de gente. Até agora a gente pode usufruir um pouco mais. Do parque (Parque do povo), dos restaurantes. Aqui antes era pouco, então era caro. Agora já é uma coisa mais acessível. Eles têm que ter para todas as clientelas. E assim, melhorou em questão de ter shopping. Sai final de semana, na sexta-feira, o happy hour você se reúne, não é uma coisa que você precisa fazer, beber, cair pra não chegar em casa, mas você consegue se reunir com os amigos. (ENTREVISTADA 3).

Nesses últimos quinze, eu não sei se são quinze... Desde que desapropriaram aquela favela lá embaixo... que acabaram com a favela o desenvolvimento veio de lá pra cá. Você vê, ali tem o Shopping Vila Olímpia, tem hotéis, tem bancos, aquela avenida (Olimpíadas) tá muito bonita! Os prédios de escritórios, as empresas, estão ali. Então isso tem acontecido nos últimos anos... São Paulo acordou, não sei por que motivo, pro valor desse terreno. Você vê que é um dos terrenos mais valorizados até né? Eu não sei... Dependendo do ranking dizem que é o quarto ou quinto dos mais caros, até o nono mais caro de São Paulo... O bairro é muito melhor agora, tem termos de 
progresso. E o progresso traz o outro lado. Mas, é muito melhor agora! Era um bairro parado no tempo. Inclusive em valor. (ENTREVISTADA 5).

Estes relatos apontaram para as dimensões de identidade e legibilidade propostas por Grinover (2007), pois neles os entrevistados demonstraram familiaridade com a configuração do traçado viário e sua identificação das vias pelos respectivos nomes. Souberam falar dos estabelecimentos comerciais que o Bairro possuía e definiram, da maneira como se registra nos documentos oficiais, a divisão do Bairro em "parte baixa" e "parte alta". Demonstraram ainda, preferência por esta nova Vila Olímpia, manifestada em suas falas, alegando que o bairro estava se tornando mais acessível, com maior praticidade comercial e com maior valorização imobiliária, mesmo apontando alguns descontentamentos, como se percebe nos relatos a seguir:

O barulho é excessivo. Já começa na quinta-feira. E se tiver um feriado, pior ainda.

Na semana é tudo muito movimentado. Meio dia você quase não anda na rua. Final de semana você não encontra uma viva alma. Nem de manhã, nem à tarde, nem noite. Aí fica esses nóias. Aí você desce tudo sossegado, se você for distraído, fica sem sua bolsa... Tem muito drogado aqui. No finalzinho da noite já nove e meia, dez horas aonde tem restaurantes com estacionamento, eles já montam as barraquinhas deles lá. Na Cardoso de Melo mesmo é cheio! Aí de manhã quando começa a funcionar o comércio, eles saem. Sábado e domingo como não funciona nada, eles continuam. (ENTREVISTADA 3).

Tá muito barulhenta (a Vila Olímpia) em função, nós não falamos dos restaurantes, porque a Vila Olímpia se tornou um polo, um point, uma segunda Vila Madalena, então o barulho! Eu coloquei vidros antirruído pra poder dormir... Então, o grande problema é esse, ela tá nessa localização central, mas ela tem poucas vias largas com acesso... As ruas não comportam o trânsito que está sendo gerado aqui pelos escritórios, pelos novos prédios de apartamentos... Ela tá crescendo desordenadamente. Aumentou muito o valor do $\mathrm{m}^{2}$. Pela localização os escritórios estão vindo muito pra cá. Prédios excelentes! Nessa quadra minha aqui atrás (Rua Cardoso de Melo) saíram cinco prédios! Numa quadra! Dois de quatro dormitórios, um de um dormitório e dois outros de dois dormitórios. Na mesma quadra! Pensa bem, na Cardoso de Melo cuja única saída é a Santo Amaro... Ela tem que escoar todo esse trânsito daqui. Então, quando estiverem todos (prédios) prontos, habitados, aí eu não sei como vai ser.... Quantos carros nós teremos novos? Vão cair todos na Santo Amaro? Quanto tempo a gente vai ficar para passar pro lado de lá? (ENTREVISTADA 5).

Tudo o que cabe ao poder público. Tudo que diz respeito ao poder público. Eu acho que é muito, muito, muito falho. Sabe? Muito falho mesmo. A segurança então nem se diga, né? Então você vê. O que que me deixa apreensiva no bairro? A segurança. Aí já engloba tudo.

Ela (Vila Olímpia) está no caminho, muito embora nos fins de semana ela seja erma. Eu tenho uma amiga que mora na Cardoso é... Ela não sai. Só se for de carro. Eu mesma se tiver que ir ao mercado, eu vou de manhã porque 
depois do almoço... De manhã você ainda vê movimento de supermercado, as pessoas indo e comprando, depois do almoço.

... Hoje mesmo comentei isso com minha filha. Você vê as calçadas, cada uma é de um jeito... Eu ando de bengala. Eu não ando na calçada, tem que andar na rua. É igual carrinho de bebê... Agora, o que eu acho que eles devem estar cansados de saber é das árvores da Vila Olímpia. Elas estão todas condenadas. Deveriam ser retiradas e cortadas... E elas estão em um local inapropriado da calçada, você não tem como passar... O mato cresce na via. Isso também devia melhorar. Eu já liguei várias vezes para a regional falando que eles venham, tal, por causa da chuva, mas não adianta. (ENTREVISTADA 7).

A sensação de insegurança manifestada pelos entrevistados supostamente decorreu de um crescente aumento da criminalidade na região, como é possível constatar em algumas matérias, como as que foram veiculadas no Jornal O Estado de São Paulo, nas edições de 14/01/2011 e 14/08/2012 ${ }^{6}$. Esta insegurança, os problemas com as calçadas estreitas e a qualidade do calçamento das vias públicas, como se verifica na imagem 7 , além do excessivo tráfego de veículos pelo Bairro, foram fatores que podem ter feito com que muitos dos entrevistados não associassem as melhorias na infraestrutura da parte baixa do Bairro com as intervenções do poder público, manifestando um descontentamento com a sua atuação.

\footnotetext{
5 “Moradores do Residencial Ignez, na Rua Quatá, Vila Olímpia, zona sul, viveram cinco horas de medo nas mãos de 15 homens armados durante um arrastão ao condomínio. O bando permaneceu no local das $21 \mathrm{~h} 30$ de quarta-feira até as $2 \mathrm{~h} 30$ de ontem. Antes da fuga, os criminosos trancaram as vítimas nos apartamentos e levaram as chaves." Disponível em:

<http://www.estadao.com.br/noticias/impresso,predio-na-vila-olimpia-e-alvo-de-arrastao,665945,0.htm>. Acesso em: 21/04/2014.

6 "Cinco assaltantes armados invadiram e roubaram, nesta terça-feira, seis apartamentos de um prédio residencial na Rua Doutor Andrade Pertence, no bairro da Vila Olímpia, bairro nobre da zona oeste de São Paulo. Os proprietários dos apartamentos, segundo informou a polícia, foram amarrados e um deles teve de ser encaminhado para atendimento médico após ter sido agredido pelos ladrões com coronhadas. A polícia foi chamada, mas os bandidos conseguiram fugir levando pertences dos moradores além de dinheiro." Disponível em: <http://www.estadao.com.br/noticias/geral,bandidos-invadem-e-roubampredio-na-vila-olimpia-em-sp, $916437,0 . h t m>$. Acesso em: 21/04/2014.
} 


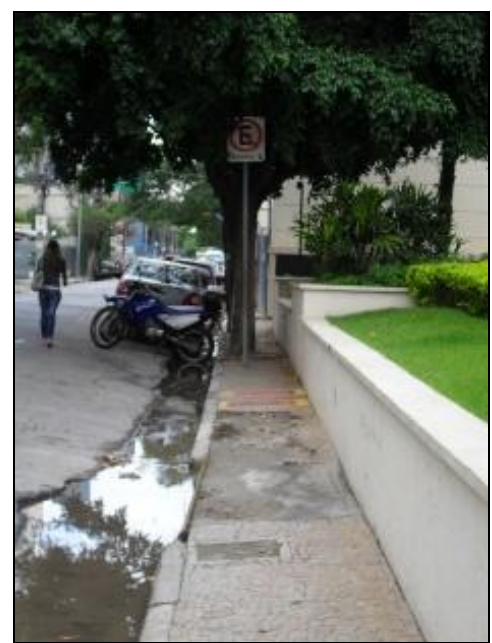

IMAGEM 7 - CALÇADA DA RUA ALVORADA.

FONTE: ARQUIVO PESSOAL (2013).

Desta maneira, assim como afirmam Ferraz (2013) e Grinover (2009), o poder público é visto como responsável por viabilizar a ideia da hospitalidade entre moradores, usuários e frequentadores eventuais de um espaço urbano. Entretanto Grinover (2009) aponta os moradores de um espaço como corresponsáveis pelas condições favoráveis à hospitalidade, tornando-se, desta maneira, também anfitriões. As calçadas na cidade de São Paulo, por exemplo, são de responsabilidade dos proprietários ou locatários dos imóveis, competindo à Prefeitura a fiscalização sobre sua construção e manutenção ${ }^{7}$. Sendo assim, ambos, Prefeitura e moradores são anfitriões deste espaço.

\section{CONCLUSÃO}

Os resultados deste estudo demonstraram que mudanças produzidas em bairros consolidados, como é o caso do bairro Vila Olímpia podem repercutir de maneira variada entre os moradores e trabalhadores do local, agradando-os ou não, pois os benefícios gerados, como a melhoria no transporte público, o alargamento de ruas, a oferta de serviços e comércio também podem gerar trânsito excessivo, maior

\footnotetext{
7 “Em 2013, a prefeitura sancionou uma nova legislação sobre calçadas. As regras estabelecem que a responsabilidade pela construção, conservação, reforma e manutenção das calçadas, que antes era apenas do proprietário do imóvel, cabe também ao usuário (locatário) do local, seja ele comercial ou residencial." PMSP. Disponível em:

<http://www.prefeitura.sp.gov.br/cidade/secretarias/subprefeituras/calcadas/index.php?p=36957>.
} 
intensidade e frequência de ruídos, aumento da criminalidade, elevação de preços, dentre outras consequências.

Repercussões contraditórias como estas, resultantes de reestruturação do espaço, também foram observadas nos estudos feitos por Pinheiro e Santos (2012), no município de Aracaju (Sergipe - Brasil), onde a revitalização do Centro Histórico trouxe mudanças espaciais significativas no espaço urbano, tanto para moradores quanto usuários eventuais da região. Tais alterações, decorrentes da necessidade de adequação do local às atividades turísticas, produziram mudanças na paisagem da área sob intervenção, mas não solucionaram problemas sociais pré-existentes, além de não favorecerem a sensação de identificação da população residente com o lugar, mesmo com a recuperação de edifícios importantes para a história e a cultura da cidade.

A ideia de uma nova organização e utilização do espaço também é tratada por Roscoche (2013, p. 831), que, ao analisar a problemática do turismo no meio urbano e a segregação socioespacial, afirma que:

[...] sendo o setor do turismo um dos mecanismos, em muitos casos, responsável pela organização e utilização do espaço, torna-se necessário que este não seja perpetuador de desigualdades e que, ao contrário, procure proporcionar os benefícios de maneira mais equitativa nos territórios ou que ainda crie condições de acessibilidade aos equipamentos e serviços básicos e turísticos de um município.

As transformações observadas no presente estudo foram, em sua maioria, uma consequência do crescimento econômico e das mudanças de uso do espaço, em decorrência deste crescimento. Entretanto, mesmo indicando pontos negativos das alterações ocorridas após os anos 1990, os entrevistados demonstraram preferir o bairro Vila Olímpia após as alterações urbanas e, através de seus relatos demonstraram perceber as dimensões da hospitalidade urbana discutidas neste estudo. Ao confirmarem a melhoria do acesso ao bairro, a implementação da sinalização que facilita a orientação e, ainda, identificação dos nomes de ruas e das partes alta e baixa do bairro, revelaram reconhecer a dimensão da legibilidade deste espaço, demonstrando identificar seus códigos e o significado de sua simbologia.

A identidade, outra dimensão da hospitalidade, pôde ser notada nas manifestações de preferência que os entrevistados apontaram ter pelo bairro Vila 
Olímpia após as alterações urbanas e na capacidade de compreender suas características e peculiaridades.

Constatou-se que os entrevistados não identificaram no poder público a responsabilidade pelas mudanças na infraestrutura do bairro, mas atribuíram a ele os problemas que persistiam, como a falta de calçamento adequado, a sensação de insegurança, o excesso de barulho e a alta dos preços.

Conclui-se que, como em muitos outros bairros, os moradores da Vila Olímpia e o poder público são responsáveis por favorecer as condições de hospitalidade existentes, pois, estas dependem da relação estabelecida entre o espaço e as pessoas que nele convivem.

\section{REFERÊNCIAS}

BAIRRO VILA OLIMPIA. Um pouco de história do bairro Vila Olímpia - São Paulo. São Paulo, 2004. Disponível em:

<http://www.bairrovilaolimpia.com.br/htmHISTORIA/HISTORIA.htm>. Acesso em: 21/07/2012.

COLMÉIASP. www.colméiasp.com.br. A associação. São Paulo. Disponível em:

<http://www.colmeiasp.com.br/associacao.html>. Acesso em: 10/11/2012.

CPTM - COMPANHIA PAULISTA DE TRENS METROPOLITANOS. CPTM. Disponível em:

<http://www.cptm.sp.gov.br/E_REDECPTM/REDE/esquema_estacao.asp?menu=9>. Acesso em: 17/09/2012.

FERRAZ, V. S. Hospitalidade urbana em grandes cidades. 265 p. Tese de Doutorado. Faculdade de Arquitetura e Urbanismo (FAU). USP. São Paulo - SP, 2013.

FIX, M. Parceiros da Exclusão. São Paulo: Boitempo, 2001.

FIX, M. São Paulo cidade global: Fundamentos financeiros de uma miragem. São Paulo: Boitempo, 2007.

FRUGOLI JR, H. A questão da centralidade em São Paulo: o papel das associações de caráter empresarial. Revista Sociologia e Política, 2001, 16, p. 51-66.

GOOGLE EARTH - Recorte geográfico estabelecido para o estudo. Acesso em: 30/04/2014. 
GRINOVER, L. A hospitalidade, a cidade e o turismo. São Paulo: Aleph, 2007.

A hospitalidade na perspectiva do espaço urbano. São Paulo, Revista Hospitalidade, 2009, v. VI, n. 1, p. 4-16.

JORNAL FOLHA DE SÃO PAULO. Operação Urbana restringe escritórios na Vila Olímpia, 2009. Disponível em:

<http://www.cadernosmetropole.net/download/cm_artigos/cm20_138.pdf > . Acesso em: 18/01/2013.

Desiquilíbrios. São Paulo 04 nov. 2012. Disponível em:

<http://www1.folha.uol.com.br/revista/saopaulo/sp0411201210.htm>. Acesso em: 30/04/2014.

KURI, P. R.; DÍAZ, M A. A. (coord.). Pensar y Habitar la ciudad: Afectividad, memoria y significado em el espacio urbano contemporâneo. México: Anthropos, 2006. p. 07-12.

LASHLEY, C.; MORRISON, A. Em busca da hospitalidade: perspectivas para um mundo globalizado. Tradução de Carlos David Szlack. Barueri: Manole, 2004.

LYNCH, K. A imagem da cidade. 3. ed. São Paulo: WMF Martins Fontes, 2011.

PINHEIRO, R. C. dos S.; SANTOS, C. A. de J. Revitalização urbana e turismo: o caso do Centro Histórico de Aracaju (Sergipe, Brasil). Turismo \& Sociedade, 2012, v. 5, n. 1, p. 275-294.

PMSP - Prefeitura do Município de S. Paulo. CEPAC. Disponível em:

$<$ http://www.prefeitura.sp.gov.br/cidade/secretarias/desenvolvimento_urbano/sp_urbani smo/cepac/index.php?p=19456>. Acesso em: 12/06/2013.

REVISTA VEJASP. Vila Olímpia: saiba como era o bairro em 1966. São Paulo. Disponível em:

<http://vejasp.abril.com.br/materia/vila-olimpia-1966>. Acesso em: 20/06/2013.

RIBEIRO, J. Histórias da Vila Olímpia. São Paulo, dez 2004. Disponível em: $<$ http://www.sampaonline.com.br/reportagens/historiadavilaolimpia.htm>. Acesso em: $14 / 09 / 2012$.

ROSCOCHE, L. F. Turismo no meio urbano e a segregação socioespacial: revisitando problemáticas. Turismo \& Sociedade, 2013, v. 6, n. 4, p. 814-834.

Recebido em: 11-05-2014.

Aprovado em: 10-06-2014. 